\title{
Endoluminal Closure of Colon Perforation with Endoscopic Band Ligation: Technical Feasibility and Safety in an In Vivo Canine Model
}

\author{
Joung-Ho Han ${ }^{1, *}$, Myounghwan Kim ${ }^{2, *}$, Tae Hoon Lee ${ }^{3}$, Hyun Kim¹, Yunho Jung ${ }^{3}$, Seon Mee Park ${ }^{1}$, Heebok Chae ${ }^{1}$, Seijin Youn ${ }^{1}$, \\ Ji Yun Shin ${ }^{4}$, In-Kwang Lee ${ }^{4}$, Tae Soo Lee ${ }^{4}$ and Seok Hwa Choi ${ }^{2}$ \\ ${ }^{1}$ Department of Internal Medicine, Chungbuk National University College of Medicine, Cheongju, ${ }^{2}$ Department of Veterinary Surgery, \\ Chungbuk National University College of Veterinary Medicine, Cheongju, ${ }^{3}$ Department of Internal Medicine, Soonchunhyang University \\ Cheonan Hospital, Soonchunhyang University College of Medicine, Cheonan, ${ }^{4}$ Department of Biomedical Engineering, Chungbuk National \\ University College of Medicine, Cheongju, Korea
}

Background/Aims: Endoscopic band ligation (EBL) is an accepted method in the management of variceal bleeding; however, there is little evidence on the safety and feasibility of EBL for the closure of bowel perforation. In this study, we aimed to evaluate the technical feasibility and efficacy of EBL in iatrogenic colon perforation by using a canine model.

Methods: We established an iatrogenic colon perforation model by using seven beagle dogs. Longitudinal 1.5- to 1.7-cm colon perforations were created with a needle knife and an insulated-tip knife, and the perforation was subsequently closed with EBL. During a 2-week follow-up period, the animals were carefully monitored and then euthanized for pathologic examination.

Results: The EBL of iatrogenic colon perforations was successful in all dogs. The mean procedure time for EBL closure with one to three bands was 191.7 seconds, and there were no immediate complications. One animal was euthanized after 3 days because of peritonitis. There were no clinical and laboratory features of sepsis or peritonitis in the remaining six animals. On necropsy, we did not find any fecal peritonitis, pericolonic abscess formation, or transmural dehiscence at the perforation site. Histopathology demonstrated inflamed granulation tissue and scar lesions replaced by fibrosis.

Conclusions: EBL might be a feasible and safe method for the management of iatrogenic colon perforations in an in vivo model.

Clin Endosc 2015;48:534-541

Key Words: Colon perforation; Endoscopic band ligation; Complication

\section{INTRODUCTION}

Various techniques for the endoluminal closure of iatrogenic colonic perforation have been reported. Some studies recommend primary endoluminal closure by using through-the-

\footnotetext{
Received: December 19, 2014 Revised: March 26, 2015 Accepted: April 3, 2015

Correspondence: Tae Hoon Lee

Division of Gastroenterology, Department of Internal Medicine, Soonchunhyang University Cheonan Hospital, Soonchunhyang University College of Medicine, 31 Suncheonhyang 6-gil, Dongnam-gu, Cheonan 31151, Korea

Tel: +82-41-570-3662, Fax: +82-41-574-5762, E-mail: thlee9@schmc.ac.kr

* Joung-Ho Han and Myung Hwan Kim contributed equally to this work as first authors.

(c) This is an Open Access article distributed under the terms of the Creative Commons Attribution Non-Commercial License (http://creativecommons.org/ licenses/by-nc/3.0) which permits unrestricted non-commercial use, distribution, and reproduction in any medium, provided the original work is properly cited.
}

scope (TTS) clips for small perforations and over-the-scope clips (OTSCs) for larger perforations as an initial choice in selected cases, especially with adequate colon preparation and early recognition of perforation. ${ }^{1-8}$ TTS endoclips are the most common devices for endoluminal closure despite the several technical limitations associated with the perforation size and anatomic site, which may cause wide gaps and/or tangential angles. OTSCs are expensive and not readily available in many countries and hospitals, whereas some newly developed devices remain as prototypes.

Endoscopic band ligation (EBL) has been widely used to control variceal or diverticular bleeding, ${ }^{9-11}$ and several reports have documented the successful endoscopic closure of iatrogenic bowel perforations by using EBL. ${ }^{12-15}$ Our group reported rescue EBL for gastric perforation resulting from endoscopic submucosal dissection (ESD) or ulcer, and for iat- 
rogenic colon perforation during endoscopy. ${ }^{15,16}$ We also have shown that the technical feasibility and efficacy of EBL in endoluminal closure were not inferior to those of TTS endoclips in an ex vivo porcine model. ${ }^{17}$

On the basis of these encouraging results, we investigated the technical feasibility and safety of endoluminal closure of iatrogenic colon perforations by using EBL in an in vivo perforation model.

\section{MATERIALS AND METHODS}

This work was approved by the Institutional Animal Care and Use Committee of Chungbuk National University (approval no. CBNUA-396-12-01) and conducted in an operation room at the laboratory animal research center. We used nine adult male beagle dogs weighing 10 to $15 \mathrm{~kg}$. To determine the size and precise location of the perforation, two animals were euthanized immediately after making multiple perforations. The remaining seven animals were euthanized 2 weeks after EBL closure. In the survival group, the animals were inspected daily for 2 weeks for clinical signs of peritonitis and sepsis. A complete blood count (SYSMEX, Kobe, Japan) and highly sensitive C-reactive protein (hs-CRP) assay (HITACHI 7600; SEKISUI, Osaka, Japan) were performed on days $0,1,3,7$, and 14. A necropsy was performed to assess fecal peritonitis, wound dehiscence, and colon pathology.

\section{Anesthesia and colonoscopy preparation}

For the experiment, the animals were maintained on a liquid diet for 3 days before bowel preparation. Then, 1 day before endoscopy, the animals were fed with $40 \mathrm{~mL}$ lactulose (Duphalac syrup; Choongwae Pharmaceutical, Seoul, Korea) twice. Finally, a warm saline enema, $100 \mathrm{~mL}$, on the day of endoscopic procedure, was performed. The experimental animals were stabilized in the left lateral position and premedicated with the subcutaneous administration of $0.02 \mathrm{mg} / \mathrm{kg}$ atropine sulfate (Je-Il Pharm, Daegu, Korea). The canines were sedated by means of an intramuscular injection of tiletamine/ zolazepam (Zoletil, $5 \mathrm{mg} / \mathrm{kg}$ ) and $2 \%$ xylazine $(1 \mathrm{mg} / \mathrm{kg}$ Rompun; Bayer, Seoul, Korea). Anesthesia was administered through intravenous injection $(0.1 \mathrm{mg} / \mathrm{kg})$ followed by continuous infusion (4 to $6 \mathrm{mg} / \mathrm{hr}$ ) of vecuronium. After tracheal intubation, the animals were ventilated with a 1:1 mixture of $1.0 \%$ to $2.0 \%$ inspired isoflurane (Ifran; Hana Pharm Co. Ltd., Seoul, Korea) and oxygen (5 to $10 \mathrm{~mL} / \mathrm{kg} / \mathrm{min}$ ).

\section{Endoscopic procedures}

An endoscope (GIF 230; Olympus Optical Co, Ltd., Tokyo, Japan) with a long transparent cap (Olympus distal attachment MH-593, outer diameter: $12.9 \mathrm{~mm}$; Olympus) attached to the tip was used. A needle knife was used to create a puncture for the artificial longitudinal incision, and an insulated-tip knife was used to make a full-thickness longitudinal perforation (Fig. 1). The size of the perforation was confirmed by passing the cap-fitted endoscope through the hole during necropsy in the first two cases. In these two animals, multiple colon perforations, of variable sizes, were made 10 to $30 \mathrm{~cm}$ from the anal verge at $5-\mathrm{cm}$ intervals, followed by immediate euthanization to determine the perforation size. The length of the harvested colon in these experiments was about 30 $\mathrm{cm}$, and the mean diameter of the perforation was $1.57 \mathrm{~cm}$ (standard deviation, 1.12). In the remaining seven animals, a 1.5 to $1.7 \mathrm{~cm}$ colon perforation was made 15 to $20 \mathrm{~cm}$ from the anal verge, followed by endoscopic closure with a pneumoactivated endoscopic variceal ligating device (MD-48170;
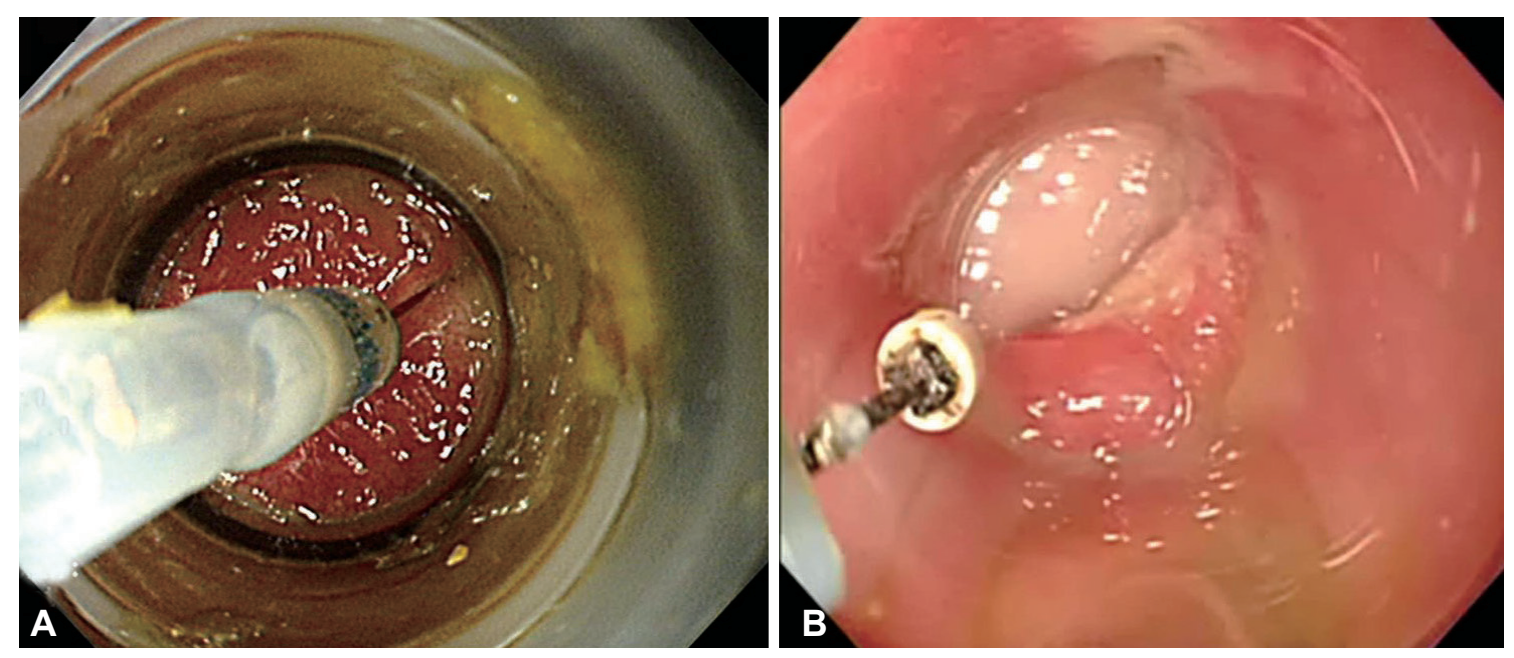

Fig. 1. An iatrogenic 1.5-cm colon perforation model. (A) A small perforation is made with a needle knife, and (B) is widened longitudinally by using an insulated-tip knife until the cap-fitted endoscope could easily pass into the peritoneal cavity. 

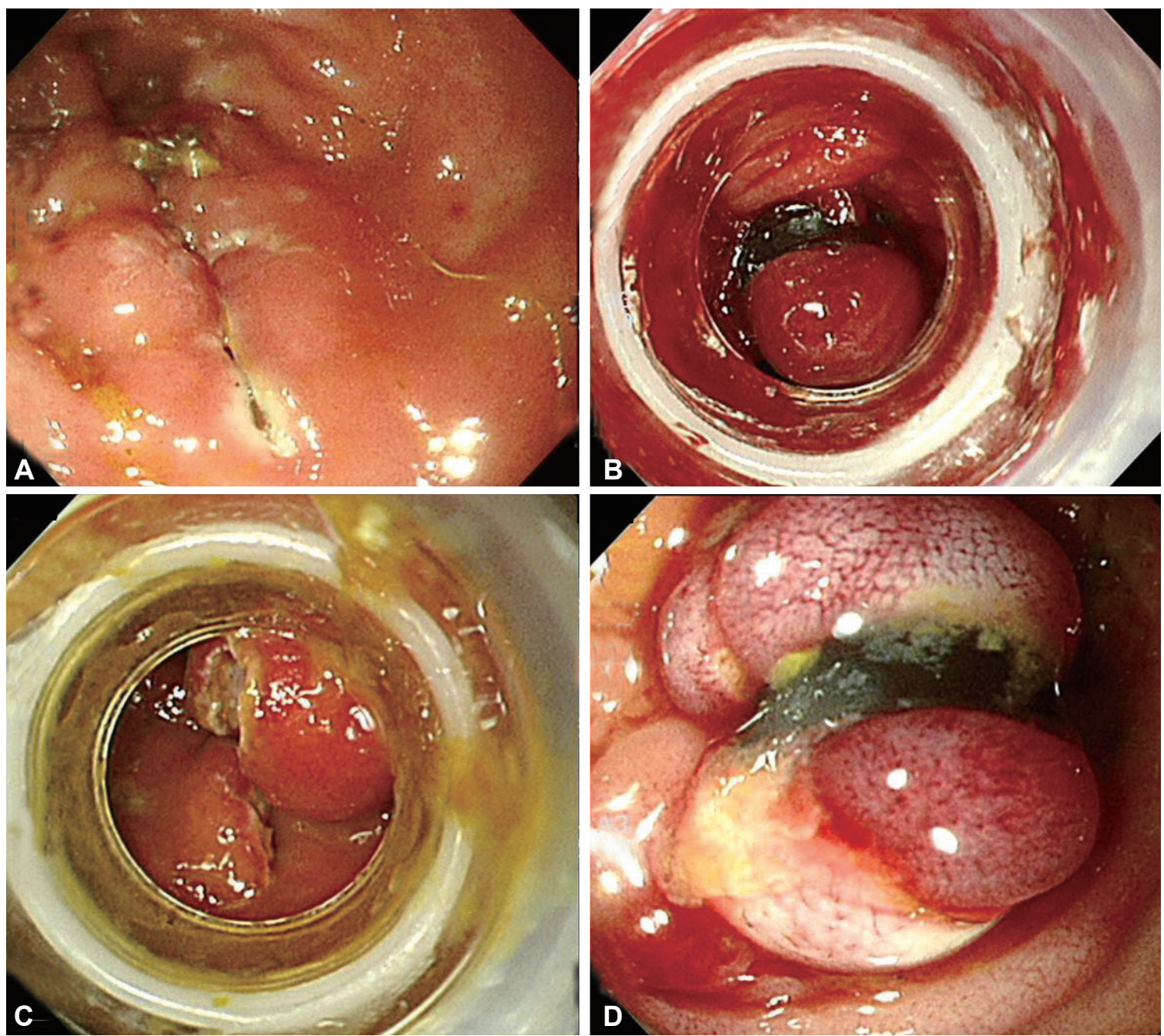

Fig. 2. (A) A full-thickness incision is made with an endoscopic knife to the colon in the iatrogenic model. (B) Endoscopic band ligation is used to make a mushroom-like banded mucosa to complete the closure. (C) A band ligates the perforation hole incompletely, although it reduces the size of the hole in a zipper-like fashion. (D) Additional band ligation closes the perforation completely.

Sumitomo Bakelite Co., Tokyo, Japan) by using the following basic sequences: the entire perforated lesion was gently extracted into the suction cap, and an elastic band was placed around the base by using a device. If closure was incomplete, additional EBL was performed until the hole was secured acceptably (Fig. 2).

\section{Follow-up and necropsy}

All animals were given $15 \mathrm{mg} / \mathrm{kg}$ ciprofloxacin orally twice per day before the procedure and maintained for 14 days after the procedure. After a 48-hour recovery period, the animals were given water and a soft diet (Merry dog; Nestle Purina Co., Seoul, Korea). All animals were carefully monitored. If there was any sign of sepsis or peritonitis, euthanasia was performed promptly. Peritonitis was diagnosed by a veterinarian when clinical findings such as lethargy, vomiting, anorexia, and abdominal rigidity developed after band ligations during a follow-up period. ${ }^{18}$

After a 2-week follow-up period, the animals were euthanized for pathologic examination. The abdominal cavity was opened through a midline incision. The intestines were clamped below the pylorus and proximal to the anus, and harvested from the body. The peritoneal cavity was closely inspected for fibrous material, abscess, and adhesions. After the isolation of the colon segment with perforation, that segment was opened longitudinally to the opposite site of the perforation to examine the mucosal side for healing. The tissue was then fixed in formalin for subsequent processing. Transverse sections of the colon across the site of perforation were taken for histopathological examination.

Four parameters were evaluated as outcome measurements: (1) the technical feasibility and procedure time of EBL to com- 
Table 1. Technical Results of Endoscopic Band Ligation in an latrogenic Colon Perforation Model

\begin{tabular}{lccc}
\hline Animal no. & No. of bands used for closure & Duration of closure, sec & \multicolumn{2}{c}{ Survival for 14 days } \\
\hline 1 & 3 & 186 & No $^{\text {a) }}$ \\
\hline 2 & 2 & 210 & Yes \\
\hline 3 & 1 & 110 & Yes \\
\hline 4 & 2 & 202 & Yes \\
\hline 6 & 2 & 280 & Yes \\
\hline 7 & 2 & 149 & Yes \\
\hline Mean (range) & 3 & 205 & Yes \\
\hline
\end{tabular}

a) This animal was euthanized on day 3 because of peritonitis.

plete perforation closure; (2) clinical and laboratory monitoring of the animals for 2 weeks to assess sepsis and peritonitis; (3) necropsy on day 14 to confirm peritonitis, adhesion, and the status of the intestinal lumen; and (4) histological parameters of the healing process.

\section{RESULTS}

\section{Technical feasibility and procedure time}

The EBL of iatrogenic colon perforations was successful in all seven animals (100\%). The mean number of bands was 2.1, and the mean procedure time was 191.7 seconds (Table 1). Although there was minor bleeding at the perforation site in three cases, EBL was able to simultaneously stop the bleeding and close the perforated hole. There were no immediate procedure-related complications. In several cases, the mesentery entered the suction cup during the suctioning of the perforation site, which resulted in a prolonged procedure time.

\section{Clinical and laboratory outcomes}

Six of the seven animals survived for 2 weeks without complication. One animal was euthanized on day 3 because of signs of sepsis and peritonitis. This animal was our first experimental attempt and had poor bowel preparation; despite water irrigation through endoscopy, the colon was not properly cleansed. In this situation, we used EBL for perforation and closure. The laboratory findings showed that the white blood cell count on day 1 was significantly more elevated than that on preprocedure day $0(p<0.01)$. Hemoglobin level, platelet count, and hs-CRP level did not show any significant changes. All laboratory data are presented in Table 2.

\section{Necropsy findings}

The necropsy findings of the case euthanized on day 3 revealed fecal peritonitis and bloody ascites at the partially
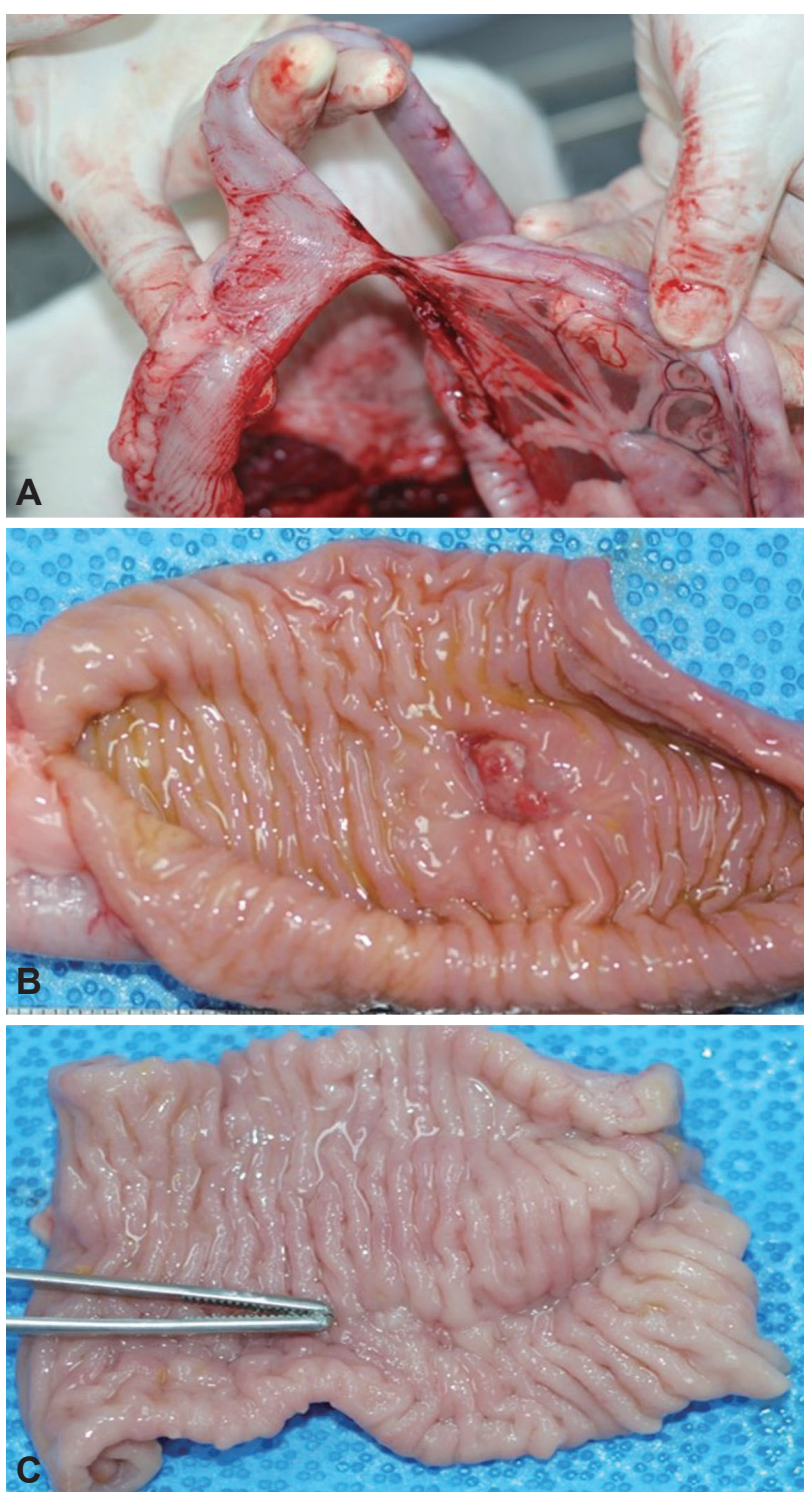

Fig. 3. Macroscopic view of a necropsy. (A) An external view of the perforation site shows local adhesion with a fibrous band and distant adhesion with the small bowel. (B) An internal view of the perforation site shows an ulcer at the healing stage and $(\mathrm{C})$ a completely healed scar. 
Table 2. Laboratory Data after Endoscopic Band Ligation on Days $0,1,3,7$, and 14

\begin{tabular}{ccccc}
\hline & $\begin{array}{c}\text { WBC, } \\
/ \mathbf{m m}^{3}\end{array}$ & $\begin{array}{c}\text { Hemoglobin, } \\
\text { g/dL }\end{array}$ & $\begin{array}{c}\text { Platelets, } \\
\mathbf{1 0}^{3} / \mathbf{m m}^{3}\end{array}$ & $\begin{array}{c}\text { CRP, } \\
\mathbf{~ m g / L ~}\end{array}$ \\
\hline Day 0 & & & & \\
\hline 1 & 3,710 & 14.7 & 298 & 0.03 \\
\hline 2 & 6,410 & 14.8 & 295 & 0.03 \\
\hline 3 & 8,220 & 16.5 & 242 & 0.03 \\
\hline 4 & 7,550 & 15.8 & 215 & 0.02 \\
\hline 5 & 7,900 & 16.8 & 300 & 0.02 \\
\hline 6 & 5,300 & 17.5 & 273 & 0.01 \\
\hline 7 & 6,700 & 15.9 & 278 & 0.01 \\
\hline Day 1 & & & & \\
\hline 1 & 12,550 & 17.9 & 319 & 0.02 \\
\hline 2 & 14,870 & 16.0 & 311 & 0.02 \\
\hline 3 & 10,780 & 17.3 & 214 & 0.02 \\
\hline 4 & 11,580 & 17.0 & 138 & 0.02 \\
\hline 5 & 21,600 & 17.8 & 226 & 0.01 \\
\hline 6 & 14,000 & 14.6 & 276 & 0.02 \\
\hline 7 & 12,700 & 15.6 & 253 & 0.01 \\
\hline
\end{tabular}

\section{Day 3}

\begin{tabular}{|crccc|}
\hline 1 & - & - & - & - \\
\hline 2 & 15,360 & 16.6 & 324 & 0.02 \\
\hline 3 & 11,550 & 17.0 & 269 & 0.03 \\
\hline 4 & 8,640 & 17.2 & 200 & 0.03 \\
\hline 5 & 7,900 & 17.5 & 225 & 0.03 \\
\hline 6 & 6,100 & 15.1 & 282 & 0.02 \\
\hline 7 & 7,800 & 16.2 & 278 & 0.02 \\
\hline
\end{tabular}

\section{Day 7}

\begin{tabular}{rrrcc}
\hline 1 & - & - & - & - \\
\hline 2 & 9,880 & 16.2 & 429 & 0.03 \\
\hline 3 & 11,820 & 16.9 & 300 & 0.02 \\
\hline 4 & 8,740 & 15.3 & 281 & 0.02 \\
\hline 5 & 7,100 & 17.0 & 223 & 0.03 \\
\hline 6 & 7,800 & 14.8 & 167 & 0.03 \\
7 & 6,700 & 13.0 & 270 & 0.03
\end{tabular}

Day 14

\begin{tabular}{rrrcc}
1 & - & - & - & - \\
\hline 2 & 12,800 & 14.2 & 278 & 0.02 \\
3 & 9,800 & 11.1 & 116 & 0.02 \\
4 & 5,700 & 12.9 & 304 & 0.02 \\
\hline 5 & 18,100 & 17.1 & 333 & 0.02 \\
\hline 6 & 8,100 & 15.3 & 201 & 0.02 \\
7 & 6,900 & 13.5 & 270 & 0.02 \\
\hline
\end{tabular}

WBC, white blood cell; CRP, C-reactive protein. open perforation site. Necropsy of the remaining six animals showed no fibrous peritonitis, fecal peritonitis, pericolic abscess, or transmural wound dehiscence. One case showed local adhesion with a thick fibrous band and distant adhesion with the small intestine (Fig. 3A). An inner view of the perforation site in three animals revealed an ulcer in the healing stage with a white coating and regenerating epithelium extending into the ulcer base (Fig. 3B), and the scar was completely covered with regenerating epithelium in three animals (Fig. 3C). These results are summarized in Table 3.

\section{Histology}

Histologic examination of the colon perforation site closed by using EBL showed the following findings: (1) healing with reepithelialization of the mucosa, (2) inflamed granulation tissue in the submucosa and serosa, and (3) defects of the muscularis propria that were replaced by fibrotic tissue. The magnitude of inflammation, healing, and fibrosis varied among the animals (Fig. 4).

\section{DISCUSSION}

Iatrogenic colon perforation is a rare but serious complication of colonoscopic procedures with relatively high morbidity and mortality rates. The incidence of perforation during diagnostic colonoscopy was reported to be $0.01 \%$; during therapeutic colonoscopy procedures including hot biopsy, polypectomy, and endoscopic mucosal resection or ESD, the incidence of perforation was reported to be $0.74 \%$ to $10.4 \%$. ${ }^{4,5,19-21}$

Some case reports have indicated a high success rate of the use of endoclips for the closure of acute iatrogenic colon perforations, and it has been accepted as an effective method for the immediate management of acute colonic perforations in limited cases for which it is technically feasible. ${ }^{3-5}$ However, endoscopic repair with endoclips can be limited in large and wide perforations or in those with tangential angles. A wide perforation is difficult to close because of slippage of the perforation edge from the clip while the clip is being maneuvered across the defect to grasp the opposite edge of the perforation. Everted perforation edges also make it difficult to grasp the tissue with endoclips.

Recently, new clips have been developed by improving the existing designs, and new suturing devices have also become available. Furthermore, the recent release of woundless natural orifice transluminal endoscopic surgery has stimulated the development of various endoscopic suturing devices. These devices include TTS clips, such as the QuickClip 2 (Olympus Inc., Center Valley, PA, USA), Resolution clip (Boston Scientific Inc., Natick, MA, USA), and Tri-Clip and Instinct clip 
Table 3. Necropsy and Pathology Results after Endoscopic Band Ligation of the Colon Perforation on Day 14 in a Survival Model

\begin{tabular}{|c|c|c|c|c|c|c|}
\hline Animal no. & $\begin{array}{c}\text { Fibrous } \\
\text { peritonitis }\end{array}$ & $\begin{array}{c}\text { Fecal } \\
\text { peritonitis }\end{array}$ & $\begin{array}{l}\text { Pericolonic } \\
\text { abscess }\end{array}$ & $\begin{array}{l}\text { Transmural wound } \\
\text { dehiscence }\end{array}$ & Adhesion & $\begin{array}{l}\text { Inner view of the } \\
\text { perforation site }\end{array}$ \\
\hline 2 & No & No & No & No & Local & Ulcer \\
\hline 3 & No & No & No & No & No & Scar \\
\hline 4 & No & No & No & No & Distant & Scar \\
\hline 5 & No & No & No & No & No & Ulcer \\
\hline 6 & No & No & No & No & No & Ulcer \\
\hline 7 & No & No & No & No & No & Scar \\
\hline
\end{tabular}
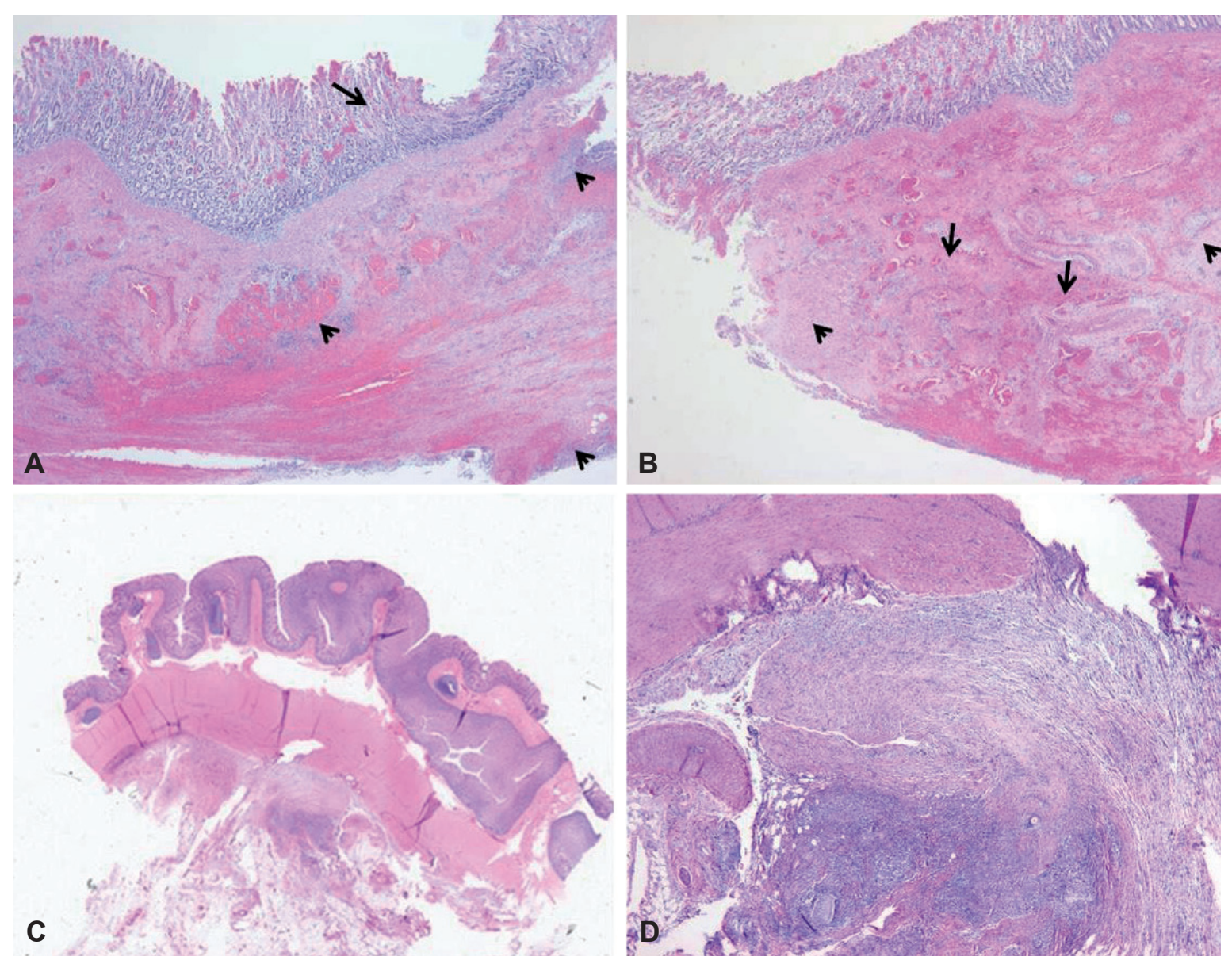

Fig. 4. Microscopic finding of the healed site of endoscopic band ligation. (A) Complete reepithelialization of the mucosa is seen (arrow). Inflamed granulation tissue remains in the submucosa and serosa (arrowheads) (H\&E stain, $\times 10$ ). (B) Defects of the muscularis propria (arrowheads indicate preexisting smooth muscle bundles) are replaced by fibrosis (arrows) (H\&E stain, $\times 10$ ). (C) The fibrotic adhesion with the small bowel is seen at the site of healing of the perforation on the serosal surface $(H \& E$ stain, $\times 1)$. (D) Severe fibrosis with chronic inflammation is observed in the pericolic fat tissue (H\&E stain, $\times 40)$.

(Cook Medical, Winston-Salem, NC, USA); the OTSC system (Ovesco Endoscopy AG, Tubingen, Germany); and endoscopic suturing devices such as T-tags (Ethicon Endo-Surgery, Cincinnati, OH, USA) and the flexible Endo Stitch (Covidien, Mansfield, MA, USA). ${ }^{2,6,8,22,23}$ Several of these devices have shown increased efficacy compared with the endoscopic clip, particularly for defects $\geq 20 \mathrm{~mm}$. However, most of these devices are at either the preclinical and clinical stages, or will be very costly, even if their clinical use is approved. Therefore, the popular use of these devices will likely be restricted to specialist endoscopists.

EBL was first introduced in 1988 for the treatment of bleeding from esophageal varices. ${ }^{9}$ Technically, EBL is a simple procedure, and EBL has been widely used in the management of nonvariceal hemorrhage from Dieulafoy's ulcer, gastric angiodysplasia, and polypectomy-induced bleeding. ${ }^{10-12}$ In 
addition, there have been recent reports of successful endoscopic closure of iatrogenic bowel perforations by using EBL after the failure of endoclips. ${ }^{15,16}$ Also, after our pilot studies on the colon in an ex vivo porcine model, ${ }^{17}$ we aimed to evaluate whether colon perforations could be closed effectively with EBL. We explored the feasibility of endoluminal closure of $15-\mathrm{mm}$ perforations by using EBL. This ex vivo porcine study showed that colonic perforations of a $1.5-\mathrm{cm}$ diameter can be closed endoscopically with EBL, with the leak pressure of EBL closure similar to that of the endoclip, whereas closure with EBL was faster and easier than that with the endoclip. ${ }^{17}$

This in vivo animal study was aimed at investigating the technical feasibility, biomechanical properties, histologic healing, and clinical outcome of the endoluminal closure of iatrogenic colonic perforations by using EBL. There was no reported clinical study on band ligation therapy for colonic perforations; therefore, in this study, we wanted to indirectly show the efficacy of band ligation by demonstrating the usefulness of a simple band ligation in an animal colon perforation model.

Technically, EBL for colon perforation suturing is a simple and fast procedure. Even in cases where the perforation is too large for ligation with a band, partial ligation could be performed and would benefit from a zipper effect. Complete suturing could be achieved by adding additional bands to the ligation. EBL is also free from problems with clips, such as clip direction and slipping. One slight issue of band ligation is that, during gas aspiration for band ligation, the serous membrane could be absorbed into the aspiration cup. However, this can be overcome by slow, gradual aspiration from the margin of perforation. In addition, delayed perforation may occur after a band ligation in lesions upturned toward the peritoneum rather than lesions protruding toward the lumen, where the intestinal movement is relatively fast. We considered this possibility, and pulled in enough of the perforation during band ligation to use two bands to make a mushroom shape. If a ligation does not include all of the surrounding tissues, it may become loose during the recovery. Another issue is that EBL may fail if the surrounding tissues are too hard for endoscopic suction. We also experienced some difficulty in aspiration with acutely inclined lesions in the colon. However, all other endoscopic suturing devices have this kind of difficulty, which is more problematic with endoscopic clips.

Unlike the stomach, which has a thick wall, the colon and the small intestine have thin walls, raising concerns that a neighboring organ or the peritoneum may be ligated together in the course of a band ligation, causing delayed perforation or damage and adhesion to that organ. However, Farrell et al. ${ }^{24}$ provided in vivo and ex vivo evidence that such a risk would be very low. Among multiple large studies comparing band ligation against clips for the treatment of colonic diverticular bleeding, none reported a case of delayed perforation, damage to a neighboring organ, or intestinal adhesion resulting from band ligation. ${ }^{25-28}$ Perforation and hemorrhage are clearly two different clinical conditions; however, band ligation itself has the same effect on the same organ, and thus there is no reason to believe that band ligation would induce a new type of complication, other than being ejected from its place owing to the movement of the colon or the small intestine. There was a case of adhesion to another organ in our study; however, it was not caused by the other organ being drawn in by the band. All of our cases were without clinical problems. The serous membrane that was drawn in while performing the aspiration may be considered a cause of adhesion; however, previous studies intentionally involved the serous membrane to allow for the suturing of large perforations and to enhance the quality of suture. ${ }^{2,29}$ Thus, suturing an appropriate amount of serous membrane together by aspiration might be helpful in preventing delayed perforation and in tightening the suture.

Results from 2 weeks of follow-up after EBL of colon perforation in seven dogs clearly indicated the stability and utility of EBL, except in one case with poor bowel preparation. Necropsy of the surviving animals also revealed that the perforation was cured without peritonitis development, as reflected by cicatrization on histopathological examination. There was no significant change in hemoglobin level, platelet count, and hs-CRP leel, except for significantly increased leukocytes on day 1 after the perforation. This may be due, in part, to the fact that the perforation was sutured immediately, reducing peritoneal contamination and the risk of peritonitis. However, hs-CRP, a more sensitive marker than leukocytes, did not change, possibly owing to the low weights of the beagles used in this study or to a characteristic of the species. Further study according to the various colon sites is needed.

This study has several notable limitations. First, this was a single-arm animal study without a control group. Future studies should include a comparison with existing endoscopic sutures, such as endoscopic clip suture or surgical suture, in terms of convenience and suture quality. Second, to maintain a tight suture, the strategy of aspirating a portion of the serous membrane to be sutured together could also be evaluated. Third, EBL was successful for perforations of $~ 1.7 \mathrm{~cm}$; however, whether it facilitates suturing of larger perforations has yet to be confirmed. A follow-up study is necessary to confirm this possibility. Finally, this perforation model was not performed at the proximal colon. Multiple bands are required for closure of a larger perforation. In such cases, the endoscopists should withdraw the endoscope repetitively. If the perforation occurred in the proximal colon, it would be a limitation for rapid closure. 
In conclusion, this study demonstrated the technical feasibility and suturing result of EBL for iatrogenic colon perforations in an in vivo animal model. In this model, EBL was observed to be safe and useful for suturing colon perforations. The early pathologic findings also indicated proper healing without serous peritoneal adhesion. EBL may also be attempted as a rescue strategy for large perforations for which endoscopic clip suture is clinically impossible, for perforations located at a particularly difficult angle, or after a failure of early endoscopic clip closure. More prospective clinical studies are necessary to address these issues.

\section{Conflicts of Interest}

The authors have no financial conflicts of interest.

\section{Acknowledgments}

This research was supported by the Wolbong Research Prize (2012) from the Korean Gastrointestinal Endoscopy Research Foundation and the Korea Healthcare Technology R\&D Project, Ministry of Health and Welfare, Republic of Korea (A100054).

\section{REFERENCES}

1. Lee TH, Bang BW, Jeong JI, et al. Primary endoscopic approximation suture under cap-assisted endoscopy of an ERCP-induced duodenal perforation. World J Gastroenterol 2010;16:2305-2310.

2. Baron TH, Wong Kee Song LM, Zielinski MD, Emura F, Fotoohi M, Kozarek RA. A comprehensive approach to the management of acute endoscopic perforations (with videos). Gastrointest Endosc 2012;76:838859.

3. Kim JS, Kim BW, Kim JI, et al. Endoscopic clip closure versus surgery for the treatment of iatrogenic colon perforations developed during diagnostic colonoscopy: a review of 115,285 patients. Surg Endosc 2013;27:501-504.

4. Mangiavillano B, Viaggi P, Masci E. Endoscopic closure of acute iatrogenic perforations during diagnostic and therapeutic endoscopy in the gastrointestinal tract using metallic clips: a literature review. J Dig Dis 2010;11:12-18.

5. Panteris V, Haringsma J, Kuipers EJ. Colonoscopy perforation rate, mechanisms and outcome: from diagnostic to therapeutic colonoscopy. Endoscopy 2009;41:941-951.

6. Matthes K, Jung Y, Kato M, Gromski MA, Chuttani R. Efficacy of full-thickness GI perforation closure with a novel over-the-scope clip application device: an animal study. Gastrointest Endosc 2011;74:13691375.

7. Yang DH, Byeon JS, Lee KH, et al. Is endoscopic closure with clips effective for both diagnostic and therapeutic colonoscopy-associated bowel perforation? Surg Endosc 2010;24:1177-1185.

8. Kirschniak A, Subotova N, Zieker D, Königsrainer A, Kratt T. The OverThe-Scope Clip (OTSC) for the treatment of gastrointestinal bleeding, perforations, and fistulas. Surg Endosc 2011;25:2901-2905.

9. Van Stiegmann G, Goff JS. Endoscopic esophageal varix ligation: preliminary clinical experience. Gastrointest Endosc 1988;34:113-117.

10. Brown GR, Harford WV, Jones WF. Endoscopic band ligation of an ac- tively bleeding Dieulafoy lesion. Gastrointest Endosc 1994;40:501-503.

11. Slivka A, Parsons WG, Carr-Locke DL. Endoscopic band ligation for treatment of post-polypectomy hemorrhage. Gastrointest Endosc 1994;40(2 Pt 1):230-232.

12. Fan CS, Soon MS. Repair of a polypectomy-induced duodenal perforation with a combination of hemoclip and band ligation. Gastrointest Endosc 2007;66:203-205.

13. Lee HN, Kim EJ, Park SK, et al. A case of a successful band ligation of a colonic perforation during diagnostic colonoscopy. Korean J Gastrointest Endosc 2010;41:176-179.

14. Moon SY, Park CH, Yoon SM, et al. Repair of an endoscopic submucosal dissection-induced rectal perforation with band ligation. Gastrointest Endosc 2009;69:160-161.

15. Han JH, Park S, Youn S. Endoscopic closure of colon perforation with band ligation; salvage technique after endoclip failure. Clin Gastroenterol Hepatol 2011;9:e54-e55.

16. Han JH, Lee TH, Jung Y, et al. Rescue endoscopic band ligation of iatrogenic gastric perforations following failed endoclip closure. World J Gastroenterol 2013;19:955-959.

17. Lee TH, Han JH, Jung Y, et al. Comparison of endoscopic band ligation and endoclip closure of colonic perforation: technical feasibility and efficacy in an ex vivo pig model. Dig Endosc 2014;26:659-664.

18. Culp WT, Zeldis TE, Reese MS, Drobatz KJ. Primary bacterial peritonitis in dogs and cats: 24 cases (1990-2006). J Am Vet Med Assoc 2009;234:906-913.

19. Hurlstone DP, Sanders DS, Cross SS, et al. Colonoscopic resection of lateral spreading tumours: a prospective analysis of endoscopic mucosal resection. Gut 2004;53:1334-1339.

20. Tanaka S, Haruma K, Oka S, et al. Clinicopathologic features and endoscopic treatment of superficially spreading colorectal neoplasms larger than $20 \mathrm{~mm}$. Gastrointest Endosc 2001;54:62-66.

21. Brooker JC, Saunders BP, Shah SG, Williams CB. Endoscopic resection of large sessile colonic polyps by specialist and non-specialist endoscopists. Br J Surg 2002;89:1020-1024.

22. Fujii T, Ono A, Fu KI. A novel endoscopic suturing technique using a specially designed so-called "8-ring" in combination with resolution clips (with videos). Gastrointest Endosc 2007;66:1215-1220.

23. Ryou M, Fong DG, Pai RD, Sauer J, Thompson CC. Evaluation of a novel access and closure device for NOTES applications: a transcolonic survival study in the porcine model (with video). Gastrointest Endosc 2008;67:964-969.

24. Farrell JJ, Graeme-Cook F, Kelsey PB. Treatment of bleeding colonic diverticula by endoscopic band ligation: an in-vivo and ex-vivo pilot study. Endoscopy 2003;35:823-829.

25. Setoyama T, Ishii N, Fujita Y. Enodoscopic band ligation (EBL) is superior to endoscopic clipping for the treatment of colonic diverticular hemorrhage. Surg Endosc 2011;25:3574-3578.

26. Ishii N, Setoyama T, Deshpande GA, et al. Endoscopic band ligation for colonic diverticular hemorrhage. Gastrointest Endosc 2012;75:382-387.

27. Zepeda-Gómez S, Marcon NE. Endoscopic band ligation for nonvariceal bleeding: a review. Can J Gastroenterol 2008;22:748-752.

28. Ahn DW, Lee SH, Park YS, et al. Hemostatic efficacy and clinical outcome of endoscopic treatment of Dieulafoy's lesions: comparison of endoscopic hemoclip placement and endoscopic band ligation. Gastrointest Endosc 2012;75:32-38.

29. Angsuwatcharakon $\mathrm{P}$, Thienchanachaiya P, Pantongrag-Brown L, Rerknimitr R. Endoscopic band ligation to create an omental patch for closure of a colonic perforation. Endoscopy 2012;44 Suppl 2 UCT$\mathrm{N}: \mathrm{E} 90-\mathrm{E} 91$. 